\title{
3 Research Square

\section{Knowledge and attitude towards pain relief in labor among final year midwifery students: A cross- sectional study}

Nigussie Simeneh Endalew ( $\nabla$ simenehn@gmail.com )

University of Gondar

Hailu Yimer Tawye

University of Gondar

Zewuditu Abdissa Denu

University of Gondar

\section{Research Article}

Keywords: knowledge, attitude, labour pain relief, labour analgesia, midwives

Posted Date: October 30th, 2019

DOl: https://doi.org/10.21203/rs.2.14255/v1

License: (c) (i) This work is licensed under a Creative Commons Attribution 4.0 International License.

Read Full License

Version of Record: A version of this preprint was published at International Journal of Surgery Open on January 1st, 2020. See the published version at https://doi.org/10.1016/j.ijso.2020.03.006. 


\section{Abstract}

Background: Poor attitudes and lack of knowledge about labour pain has long been demonstrated to burden the health professionals, as well as the women. In developing countries, labour analgesia practice is not well established and undermined. Therefore, the aim of this study was to explore final year midwifery students' knowledge and attitudes towards pain relief during labour, at University of Gondar, Northwest Ethiopia.

Methods: A cross-sectional study was conducted among final year undergraduate midwifery students using structured, and self-administered questionnaire $(n=130)$. Descriptive statistics were performed. Results were presented using narrations, means and standard deviations, percentage, figure and tables. Univariate analysis was used to assess the association between demographic variables with poor knowledge and attitudes. P-value below 0.05 level of significance was used to identify the statistical significance of factors for knowledge and attitude about pain relief during labour.

Results: Of 130 students participated, the majority, $88 \%$ of respondents understood that women can feel moderate to severe pain during labour. However, only less than half of the participants had knowledge of labour pain should be relieved. The majority, $70 \%$ of students did not have awareness about the methods of labour analgesia.

Conclusion: Although the majority of final year midwifery students were agreed with women can feel moderate to severe labour pain, almost more than half of the students were not aware of the painless labour in hospital. Most of the students believed that pharmacologic methods of labour analgesia will affect the labour, baby, and mother. Therefore, considerable attention in preservice teaching and training about labour pain and analgesia for midwifery students is recommended.

\section{Introduction}

Parturients experience labour pain of varying degrees, ranging from moderate to severe pain during the first and second stages of labor. The progression, intensity, characteristics, as well as the cause of first and second stage of labour pain varies greatly among women ${ }^{(1-5)}$. When pain during labor is severe it may adversely affect parturient and fetus. Particularly those parturient with cardiac co-morbidity are at high risk. Therefore, effective pain relief in labour is not only humane, but has vast physiological and psychological benefits for both the mother and the baby (4-7).

Currently, the practice of pain relief during labour is become a growing area. Several controversies have existed since its evolution from the biblical myths to date. However, apart from medical indication, maternal request signifies sufficient justification for labour pain analgesia. In many developed countries, labour analgesia is considered an important part of ante-natal and intra/post-partum care. During antenatal care for women with fixed cardiac output, planning the method of labour analgesia is becoming a routine practice ${ }^{(7-9)}$. 
Nowadays, there are many methods of pain relief in labour including pharmacological and nonpharmacological. The essentials of obstetric pain relief methods must be safe, simple, effective, not interfering with labour progression, and ideally should preserve fetal homeostasis ${ }^{(3,7,10)}$. There is a wide spectrum of non-pharmacological options available for pain relief in labour include psychological therapies $(7,11,12)$, continuous social support $(7,11,12)$, mind-body intervention $(7,11,12)$, the use of transcutaneous electrical nerve stimulator $(\operatorname{TENS})^{(13,14)}$, acupuncture $(15,16)$. The pharmacological analgesia for labour include non-opioids (ketamine) ${ }^{(7)}$, opioids (pethidine, morphine, and fentanyl) ${ }^{(3,7,17}$, 18), inhalational analgesia (a 50:50 mix of oxygen/nitrous oxide, and volatile agents) ${ }^{(3,7)}$, and regional analgesia for labour [epidural analgesia ${ }^{(19,20)}$, combined spinal-epidural, and peripheral nerve blocks] ${ }^{(3,7)}$. The effectiveness and adverse events of these methods of pain relief in labour varies. Overall, the available evidence suggests that epidural labour analgesia remains the gold standard, and currently it is the method used widely.

Studies have shown that various barriers contributing to optimal treatment of labour pain and utilization of labour analgesia include health professional related barriers, system related barriers, and patientrelated barriers. Among those, health care provider related barriers are the main barriers, the easiest to be assessed and measured, and to be corrected in many low and middle-income countries such as Ethiopia. A lack of knowledge, poor attitudes, and unavailability of labour analgesia options are considered to be the main barriers that influences utilization of labour analgesia in low resource settings $(2,21-23)$.

An increasing body of evidences showed that many health care professionals lack adequate knowledge and attitude for effectively managing labour pain, leaving many women and their baby to endure a reduced functional and psychological quality of life $\mathrm{e}^{(22,23)}$. This poor knowledge and attitudes begins in basic educational programs ${ }^{(24-26)}$. Studies on students' knowledge and attitude about pain relief in labour are limited. However, there are studies regarding graduate students' (nursing, midwifery, pharmacy, and medical students) about pain management in general, and inadequate knowledge of pain management has been reported ${ }^{(26-28)}$.

Ethiopia is a low-income country and working hard to achieve Sustainable Development Goals 4, and Ministry of Health is focusing on a very important part of pregnancy. However, the issue of obstetric analgesia as part of maternal care is not a common practice and often neglected in Ethiopia. This may have been influenced by several factors such as awareness and experience of health care providers, acceptability and availability, restricted training and teaching about labour analgesia. Midwives are the health care professionals that pregnant women come in close contact with commonly in Ethiopia. To date there is no published data on new graduate midwives' awareness and attitudes of pain relief in labour and the options or methods of labour analgesia in Ethiopia. In addition, newly graduate midwives can have an effective role in establishing labour analgesia service and in raising of awareness of mothers. For this purpose, therefore, we conducted a cross-sectional study to assess final year midwifery students' knowledge and attitude towards pain relief in labour. 


\section{Methods}

\section{Study design and Participants}

After obtaining ethical approval from University of Gondar College of Medicine and Health Sciences Research Ethics Committee of Department of Anaesthesia, a cross-sectional study design was employed. College of Medicine and Health Sciences, a public higher educational institute established in 1954, is the pioneer in teaching different health care professionals including midwives in Ethiopia. The department of midwifery were intentionally selected since midwives are the one that directly participate with pregnant women care. Those final year midwifery students graduated in 2017 at University of Gondar were included in the study. Of 131 final year students, 64 were in the extension program, and 67 were regular program.

\section{Instrument}

After written informed consent, students were requested to complete the structured, self-administered questionnaire. A questionnaire that containing 20 close ended items were prepared based on a review of questionnaires used in other studies ${ }^{(22,29)}$. The questionnaire consisted two sections. The first part of the questions covered socio-demographic characteristics of participants. The second section (15 items) focused on, and assessed knowledge, attitudes and concerns regarding labour analgesia. These includes: labour pain related issues, options of labour analgesia and WHO analgesic ladder, general effect of labour pain, perception of barriers to labour pain and analgesia, and attitude toward future education. On the second section, the first eight questions assessing the students' knowledge and attitudes towards labour analgesia, three-degree scales were used. The last seven items were asking the participants to search the correct answers about students' concern regarding use of labour analgesia. On the last seven items, the participants were informed to select more than one answers if it is applicable, and participants were also asked to provide free text at 'other (please specify)' option.

\section{Data collection}

After properly explaining the aim of the study, a structured self-administered questionnaire was handed by two investigators (HF, HN) to students. To ensure the quality of data, the tools was filled, checked for completeness and returned quickly by the students at the end of their class room (first week of April/2017). To ensure the students neither to consult internets nor discuss among themselves, information was provided by the data collectors.

\section{Data analysis}

Descriptive statistics were used to summarize socio-demographic and outcome variables. Univariate analysis (student-test, chi-square test or Mann-Whitney as appropriate), using SPSS version 20, were 
performed to analyze factors that determine poor knowledge.

\section{Results}

\section{Socio-demographic characteristics of study participants}

A total of 130 final year students was recruited in this study out of presumed 131 students who graduated in first July 2017. Of these, 76(58.5\%) were females and the mean age of students was $23.6+1.89$. The number of students in both programs (regular and extension) was almost equivalent (66 and 64 , respectively) [table1].

\section{Knowledge and attitude towards labour analgesia}

The students were assessed for their expectation about labour pain and 89 (68.5\%) of participants expected pregnant women to feel some degree of pain during labour. Of $68.5(n=89)$ students who understood that woman expected to feel pain, $30 \%$ and $57 \%$ of students expected women in labour to experience moderate and severe intensity of pain, respectively. From 130 students, 102(78\%) of them reported that they did not had any previous education or training regarding labour pain and analgesia.

Only $6(5 \%)$ of the students in this study have been asked to provide simple analgesics for laboring mother under supervision. Regarding student's knowledge of the WHO analgesic ladder, majority $108(83 \%)$ of them did not have knowledge. Of 38 (29\%) students who had knowledge about methods of labour analgesia, majority reported that they knew about non-pharmacologic (emotional support $=38$ ) and simple analgesic (paracetamol or diclofenac $=29$ ). Systemic opioids, regional labour analgesia, and Entonox were not considered as labour analgesia by respondents [table 2].

A total of $84(65 \%)$ students had concerns towards pharmacologic method of labour analgesia. Their concerns were the baby will be affected $31(37 \%)$, labour related $48(57 \%)$, and it may lead to maternal complications 5(6\%) [table 3].

On the univariate analysis, there were no statistically significant association between student's sociodemographic characteristics and their knowledge on labour analgesia related variables.

\section{Discussion}

Labour is a natural process associated with moderate to severe painful event that pregnant mothers likely to experience. Providing safe pain relief in labor is an important aspects of Sustainable Development Goal(SDG) 4 for better birth outcome and maternal wellbeing $\left.{ }^{(5,29,30}\right)$. The present study revealed that the overall knowledge and attitude towards labour pain and analgesia among midwifery graduate class 2017 were consistently poor in most outcomes. 
Regarding this issue, there are a small number of studies conducted among health care professionals and lack on midwifery students. In this cross-sectional study, the majority of midwifery students understood that laboring mothers can experience moderate to severe intensity of pain and most student reported that labour pain should be eased. Our finding is in line with study done in Nigeria among 95 maternal health care providers (including midwife students) $94.8 \%$ agreed that pain relief in labour is needed $^{(2)}$. Another study from Iran showed that majority of midwifes $(71.1 \%)$ were aware that women feels severe pain in labour ${ }^{(31)}$. Similarly, a recent study in Ethiopia ${ }^{(22)}$ shows $77 \%$ and $79 \%$ of maternal health care providers were understand labour pain should be relieved and expected women to experience moderate to severe pain during labour, respectively and which were $68 \%$ and $88 \%$ in this study. However, participants in our finding are less informed than the above studies that labour pain should be relieved. This could be explained by we include students only, in contrast to the above studies in which participants were in highest qualification and different in terms of profession (such as consultant anaesthetist and obstetrician). Students usually have inadequate knowledge and skill due to less experience and exposure to clinical practice.

Due to the multifactorial and complex pathophysiologic nature of pain, its management requires multimodal and based on WHO analgesic ladder; pharmacologic and non-pharmacologic labour analgesics. The pharmacological methods known are simple analgesic, parenteral opioids, epidural analgesia, 50:50 nitrous oxide/oxygen(Entonox $)^{(3,7)}$, inhalational agents and peripheral nerve blocks ${ }^{(3,}$ 32). Some of the non-pharmacologic labour analgesics include psychological therapies, continuous social support, mind-body intervention ${ }^{(11,12)}$, the use of transcutaneous electrical nerve stimulator (TENS) ${ }^{(13,14)}$, acupuncture $^{(15,16)}$. Despite the best evidence-based methods of labour analgesia are available currently, its utilization in low-income countries is not established yet. A cross-sectional study done in Ethiopia showed that the utilization of non-pharmacologic methods of labour analgesia was $40.1 \%$. in this study, all maternal health care providers used non-pharmacologic methods while the utilization of pharmacologic labour analgesia were found to be zero ${ }^{(33)}$. Similar with other studies ${ }^{(2,34)}$, our survey found that midwifery students level of knowledge about the available pharmacologic methods of labour analgesia were low.

From pharmacologic methods of labour analgesia, epidural analgesia $(19,20,35)$ remains the gold standard followed by systemic opioids ${ }^{(17,18)}$, and Entonox ${ }^{(3,7)}$, in most developed countries, based on the finding of several studies. In the present survey, the reason for midwife students lack of knowledge towards pharmacologic methods of labour analgesia might be due majority of students were not taught labour analgesia during their training program (78\%), as non-pharmacologic is the most commonly given form of labour pain relief in our setup, the students are not getting practical exposure because there is no established labour analgesia service.

In our study, most participants have shown negative attitude towards labour analgesia which is in contrast to other studies $(2,21,34)$. Major reason stated by our participants as barriers are lack of awareness of maternal health care providers, labour pain is not a priority, and labour pain and analgesia 
is not included as part of their training program. Poor attitude towards the use of pharmacologic labour analgesia were also observed among students, 84 of students were concerned about the effect of pharmacologic methods on the baby, labour progress and mother. Similar concerns were found by previous studies $^{(22,31,34)}$. Establishing labour analgesia service in teaching hospitals, inclusion of labour pain and analgesia in curriculums, continuing preservice training and education could be some of useful assets in this regard.

In low resource settings, such as Ethiopia midwives are most commonly the health care providers in which care of pregnant women is covered by. Therefore, it essential that midwifery students need to improve on their knowledge and change on attitude towards labour analgesia.

The strength of our study is its consideration of a clinically important topic and high response rate.

Our study limitations included the fact that we did not calculate the sample size and this may influence the generalizability of the study. Additionally, just one cadre of healthcare provider were assessed.

In conclusion, this survey demonstrated that although final year midwifery students understand and agree that labour is painful and should be treated there were still lack of knowledge and negative attitude towards labour pain management. There is a need to provide preservice education and training for midwifery students and should be established in the teaching hospitals.

\section{Declarations}

\section{Acknowledgments}

The authors thank University of Gondar for approving the study and participants for giving their time to fill the questionnaires.

\section{Author contribution}

HY conducted the study, participated in the data analysis, and interpreted the findings. HY, ZA, and NS participated in the design of the study, data analysis, drafting and revising the paper and agree to be accountable for all aspects of the work.

\section{Conflict of interest}

The authors report no conflicts of interest in this work.

\section{References}

1. Olayemi O, Adeniji R, Udoh E, Akinyemi O, Aimakhu C, Shoretire K. Determinants of pain perception in labour among parturients at the University College Hospital, Ibadan. Journal of obstetrics and 
gynaecology. 2005;25(2):128-30.

2. Ogboli-Nwasor E, Adaji S, Bature S, Shittu O. Pain relief in labor: a survey of awareness, attitude, and practice of health care providers in Zaria, Nigeria. Journal of pain research. 2011;4:227.

3. Findley I, Chamberlain G. ABC of labour care: relief of pain. BMJ: British Medical Journal. 1999;318(7188):927.

4. Brownridge P. The nature and consequences of childbirth pain. European Journal of Obstetrics \& Gynecology and Reproductive Biology. 1995;59:S9-S15.

5. Jones L. Pain management for women in labour: an overview of systematic reviews. Journal of Evidence-Based Medicine. 2012;5(2):101-2.

6. Lowe NK. The nature of labor pain. American journal of obstetrics and gynecology. 2002;186(5):S16S24.

7. Clyburn P, Collis R, Harries S. Obstetric anaesthesia for developing countries: OUP Oxford; 2010.

8. Goetzl L. ACOG Practice Bulletin. Clinical Management Guidelines for Obstetrician-Gynecologists Number 36, July 2002. Obstetric analgesia and anesthesia. Obstetrics and gynecology. 2002;100(1):177-91.

9. Anesthesia ASoATFoO. Practice guidelines for obstetric anesthesia: an updated report by the American Society of Anesthesiologists Task Force on Obstetric Anesthesia. Anesthesiology. 2007;106:843-63.

10. Antenatal E. Perinatal and Postpartum care. WHO EURO, Copenhagen. 2002.

11. Brown ST, Douglas C, Flood LP. Women's evaluation of intrapartum nonpharmacological pain relief methods used during labor. The journal of perinatal education. 2001;10(3):1.

12. Tournaire $M$, Theau-Yonneau A. Complementary and alternative approaches to pain relief during labor. Evidence-based complementary and alternative medicine. 2007;4(4):409-17.

13. Bedwell C, Dowswell T, Neilson JP, Lavender T. The use of transcutaneous electrical nerve stimulation (TENS) for pain relief in labour: a review of the evidence. Midwifery. 2011;27(5):e141-e8.

14. Peng T, Li X-t, Zhou S-f, Xiong Y, Kang Y, Cheng H-d. Transcutaneous electrical nerve stimulation on acupoints relieves labor pain: a non-randomized controlled study. Chinese journal of integrative medicine. 2010;16(3):234-8.

15. Lee $\mathrm{H}$, Ernst E. Acupuncture for labor pain management: a systematic review. American journal of obstetrics and gynecology. 2004;191(5):1573-9.

16. Kvorning TN, Nilsson M, Löfberg L, Algotsson L, Åkeson J. Acupuncture for pain relief during childbirth. Acupuncture \& electro-therapeutics research. 1998;23(1):19-26.

17. Ullman R, Smith L, Burns E, Mori R, Dowswell T. Parenteral opioids for maternal pain relief in labour. Cochrane Database of Systematic Reviews. 2008;9.

18. Anderson D. A review of systemic opioids commonly used for labor pain relief. Journal of Midwifery \& Women's Health. 2011;56(3):222-39. 
19. Nystedt A, Edvardsson D, Willman A. Epidural analgesia for pain relief in labour and childbirth-a review with a systematic approach. Journal of clinical nursing. 2004;13(4):455-66.

20. Howell C. Epidural versus non-epidural analgesia for pain relief in labour. The Cochrane database of systematic reviews. 1999;3.

21. Kannan B, Rengasamy CK. Attitude of obstetricians regarding labour analgesia and limitations in practising it. International Journal of Reproduction, Contraception, Obstetrics and Gynecology. 2017;6(2):388-91.

22. McCauley M, Stewart C, Kebede B. A survey of healthcare providers' knowledge and attitudes regarding pain relief in labor for women in Ethiopia. BMC pregnancy and childbirth. 2017;17(1):56.

23. Nabukenya MT, Kintu A, Wabule A, Muyingo MT, Kwizera A. Knowledge, attitudes and use of labour analgesia among women at a low-income country antenatal clinic. BMC anesthesiology. 2015;15(1):98.

24. Lasch K, Greenhill A, Wilkes G, Carr D, Lee M, Blanchard R. Why study pain? A qualitative analysis of medical and nursing faculty and students' knowledge of and attitudes to cancer pain management. Journal of palliative medicine. 2002;5(1):57-71.

25. Gordon DB, Dahl JL, Miaskowski C, McCarberg B, Todd KH, Paice JA, et al. American pain society recommendations for improving the quality of acute and cancer pain management: American Pain Society Quality of Care Task Force. Archives of internal medicine. 2005;165(14):1574-80.

26. Eyob T, Mulatu A, Abrha H. Knowledge and Attitude towards Pain Management among Medical and Paramedical students of an Ethiopian University. J Pain Relief. 2013;3(127):2167-846.

27. Latchman J. Evaluating knowledge and attitudes of undergraduate nursing students regarding pain management. 2010.

28. Plaisance L, Logan C. Nursing students' knowledge and attitudes regarding pain. Pain Management Nursing. 2006;7(4):167-75.

29. James JN, Prakash KS, Ponniah M. Awareness and attitudes towards labour pain and labour pain relief of urban women attending a private antenatal clinic in Chennai, India. Indian Journal of anaesthesia. 2012;56(2):195.

30. Wong CA. Advances in labor analgesia. International journal of women's health. 2009;1:139.

31. Dehghanpisheh L, Sabetian G, Fatahi Z. Painless delivery.

32. Leeman L, Fontaine P, King V, Klein MC, Ratcliffe S. The nature and management of labor pain: part II. Pharmacologic pain relief. American family physician. 2003;68(6):1115-20.

33. Bitew A, Workie A, Seyum T, Demeke T. Utilization of Obstetric Analgesia in Labor Pain Management and associated Factors among Obstetric Care Givers in Amhara Regional State Referral Hospitals, Northwest Ethiopia: A Hospital based Cross Sectional Study. Journal of Biomedical Sciences. 2016.

34. Taneja B, Nath K, Dua C. Clinical audit on the existing attitudes and knowledge of obstetricians regarding labour analgesia. Indian J Anaesth. 2004;48(3):185-8. 
35. El-Wahab N, Robinson N. Analgesia and anaesthesia in labour. Obstetrics, Gynaecology \& Reproductive Medicine. 2011;21(5):137-41.

\section{Tables}

Table 1: Socio-demographic characteristics of study participants $(n=130)$

\section{variables}

Sex: Male/Female

Age, year*

Religion:

Orthodox

Muslim

Protestant

Catholic

Others

Study program type:

Regular

Extension

Previous years academic performance(CGPA)*: regular/extension

\section{Frequency}

Percentage

$54 / 76$

$41.5 / 58.5$

$23.6 \pm 1.89$

82

63.1

25

19.2

23

17.7

0

0

66

64
0

50.8

49.2

Table 2: Knowledge and attitude towards labour analgesia $(n=130)$ 


\begin{tabular}{|c|c|c|c|}
\hline$\overline{\text { [EM }}$ & Response & Frequency & Percentage \\
\hline hould women & Yes & 89 & 68.5 \\
\hline xpect to feel & No & 11 & 8.5 \\
\hline ain? & Not sure & 30 & 23 \\
\hline lave you had & Yes & 9 & 7 \\
\hline ny previous & No & 102 & 78 \\
\hline $\begin{array}{l}\text { ducation on } \\
\text { ibour } \\
\text { nalgesia? }\end{array}$ & Not sure & 19 & 15 \\
\hline o you think & Yes & 62 & 48 \\
\hline ain in labour & No & 35 & 27 \\
\hline $\begin{array}{l}\text { hould be } \\
\text { slieved? }\end{array}$ & Not sure & 33 & 25 \\
\hline lave you been & Yes & 6 & 5 \\
\hline sked to & No & 78 & 60 \\
\hline $\begin{array}{l}\text { rovide pain } \\
\text { əlieve under } \\
\text { upervision? }\end{array}$ & Not sure & 46 & 35 \\
\hline $\begin{array}{ll}\text { Jould } \quad \text { you }\end{array}$ & Yes & 41 & 32 \\
\hline rovide pain & No & 17 & 13 \\
\hline $\begin{array}{l}\text { slief if you } \\
\text { ad the } \\
\text { ssource after } \\
\text { ou graduate? }\end{array}$ & Not sure & 72 & 55 \\
\hline $\begin{array}{ll}\text { lave } \quad \text { you }\end{array}$ & Yes & 9 & 7 \\
\hline eard of the & No & 108 & 83 \\
\hline $\begin{array}{l}\sqrt{\mathrm{HO}} \\
\text { nalgesic } \\
\text { idder? }\end{array}$ & Not sure & 13 & 10 \\
\hline o you have & Yes & 84 & 65 \\
\hline oncerns with & No & 32 & 24 \\
\hline $\begin{array}{lr}\text { sing } & \text { pain } \\
\text { əlief } & \text { in } \\
\text { ıbour? } & \end{array}$ & Not sure & 14 & 11 \\
\hline Jhat intensity & No pain & 0 & 0 \\
\hline f pain would & Mild & 11 & 13 \\
\hline ou expect & Moderate & 27 & 30 \\
\hline lem & Severe & 51 & 57 \\
\hline xperience? & Total & 89 & 100 \\
\hline
\end{tabular}




\begin{tabular}{|c|c|c|c|}
\hline Jhat types of & None & 92 & 70 \\
\hline rethods of & Emotional support & 38 & 29 \\
\hline ibour & Breathing exercise & 17 & 17 \\
\hline nalgesia do & Massage & 22 & 17 \\
\hline ou know? & TENS & 0 & 0 \\
\hline & Acupuncture & 0 & 0 \\
\hline & No-opioids & 29 & 22 \\
\hline & Opioids & 0 & 0 \\
\hline & Inhalational agents & 0 & 0 \\
\hline & $50: 50$ mix of $\mathrm{O} 2 / \mathrm{N} 2 \mathrm{O}$ & 0 & 0 \\
\hline & $\begin{array}{l}\text { Regional } \\
\text { analgesia }\end{array}$ & 0 & 0 \\
\hline Jhy do you & To relieve pain & 33 & 25 \\
\hline link pain & To relieve stress & 8 & 6 \\
\hline hould be & To feel confident & 12 & 9 \\
\hline əlieved? & To enjoy the experience & 9 & 7 \\
\hline & Total & 62 & 48 \\
\hline Jhy do you & Labour is a natural process & 16 & 12 \\
\hline link labor & It will take labour longer & 8 & 6 \\
\hline ot be & It will affect the baby & 9 & 7 \\
\hline əlieved? & Will cause complication & 2 & 5 \\
\hline & Total & 35 & 100 \\
\hline Jhat are the & Lack of awareness of parturient & 6 & 4 \\
\hline sr parturients & Lack of awareness of medical professional & 27 & 21 \\
\hline ) receive & & & \\
\hline nalgesia in & Cultural norm & 9 & 7 \\
\hline & Pain is not a priority for laboring mother & 21 & 16 \\
\hline & Financial constraints & 7 & 5 \\
\hline & Lack of availability & 19 & 15 \\
\hline & Did not included as part of teaching curriculum & 41 & 32 \\
\hline & Total & 130 & 100 \\
\hline
\end{tabular}




\begin{tabular}{|c|c|c|c|}
\hline$\overline{\mathrm{EM}}$ & Frequency & & Percentage \\
\hline will affect the baby? & It will affect the baby's breathing & 14 & 45 \\
\hline \multirow[t]{4}{*}{$=31)$} & It will affect bonding & 5 & 16 \\
\hline & It will affect breastfeeding & 12 & 39 \\
\hline & It may affect baby's development & 0 & 0 \\
\hline & Total & 31 & 100 \\
\hline will affect the labour? & It will affect contraction & 16 & 33 \\
\hline \multirow[t]{5}{*}{$=48)$} & Make the labour unnatural & 11 & 23 \\
\hline & Affect the mother's ability to push & 12 & 25 \\
\hline & Increase operative delivery and cesarean & 9 & 19 \\
\hline & section & 48 & 100 \\
\hline & Total & & \\
\hline will affect the mother? & Physical side effect & 5 & 100 \\
\hline \multirow[t]{3}{*}{$=5)$} & It may cause sleep & 0 & 0 \\
\hline & It may cause addiction & 0 & 0 \\
\hline & Total & 5 & 100 \\
\hline
\end{tabular}

\section{Supplementary Files}

This is a list of supplementary files associated with this preprint. Click to download.

- Table2.docx

- Table1.docx 